\title{
Seaweed Dietetic Food for the Functional Gastrointestinal Complaint Treatment
}

\author{
Juris Pokrotnieks ${ }^{1}$, Aleksey Derovs ${ }^{2}$, Elena Derova ${ }^{2}$, Diana Zandere ${ }^{\mathbf{1}^{*}}$, Alexei Odinets ${ }^{3}$, \\ Vladimir Mishailov ${ }^{4}$ \\ ${ }^{1}$ Gastroenterology, Hepatology and Nutrition Centre, Pauls Stradins Clinical University Hospital, Riga, Latvia; ${ }^{2}$ Department of \\ Endoscopy, Latvian Maritime Medicine Centre, Riga, Latvia; ${ }^{3}$ Institute for Biomedical Problems of Russian Academy of Sciences, \\ Moscow, Russia; ${ }^{4}$ Russian Scientific Centre of Rehabilitation Medicine \& Health Resorts, Moscow, Russia. \\ Email: *diana_zandere@yahoo.co.uk
}

Received June $6^{\text {th }}, 2013$; revised July $6^{\text {th }}, 2013$; accepted July $13^{\text {th }}, 2013$

Copyright (C) 2013 Juris Pokrotnieks et al. This is an open access article distributed under the Creative Commons Attribution License, which permits unrestricted use, distribution, and reproduction in any medium, provided the original work is properly cited.

\begin{abstract}
Despite the common nature of dyspeptic complaints, the treatment is still a problem. There is very little research done on the impact of dietary nutrition on the general health of the patients with dyspeptic complaints and overall nutritional safety. Study Objective: To evaluate the clinical effectiveness of the brown seaweed dietary product "Vitamarine" for the treatment of dyspepsia, as well as product safety. Material and Methods: An open, uncontrolled pilot study with questionnaires before and after the vitamarine course with the patient's self-perception reports. Data were processed with multivariate analysis. Results: The study included 46 patients with 45 valid end result questionnaires for data processing. After 8 to 10 days use of vitamarine, 33 (76.8\%) patients noted symptom disappearance or significant improvement, no improvement of symptoms or their increase was noted by 10 patients $(23.2 \%)$. Complaints about weakness, fatigue and rapid tiredness significantly decreased or disappeared entirely $(p=0.04)$, including months long epigastric pain $(p=0.02)$ and constipation $(p=0.01)$. Conclusions: 1$)$ Use of the dietetic food product "Vitamarine" with a dose of $50-60 \mathrm{~g}$ per day in two cases out of three improve the general well-being of the patients: months long dyspeptic abdominal pain and constipation disappear or significantly decrease. 2) In the first $8-10$ days of the vitamarine course, clinical effectiveness already can be noted. 3) Use of vitamarine is safe, including patients with a history of allergies to medications, elderly and patients with concomitant diseases.
\end{abstract}

Keywords: Dyspeptic Complaints; Seaweed Dietary Products; Laminaria; Vitamarine

\section{Introduction}

Functional gastrointestinal disorders that can be divided into upper (mainly oesophagus, stomach and duodenum) and lower (intestines) disorders are very common. Diagnosed functional dyspepsia and irritable bowel syndrome significantly impair the quality of life. Due to the fact that the aetiology and pathogenesis are still unknown, treatment is symptomatic. Despite the supposedly "functional" nature of these diseases, the annual cost in the USA is estimated to be an impressive amount: $\$ 5049$ for the irritable bowel syndrome, $\$ 6140$ for diarrhoea, $\$ 7522$ for constipation and $\$ 7646$ for the abdominal pain [1]. In the case of functional dyspepsia, H. pylori eradication course, short term use of acid-reducing agents, anti-spasmolytics, prokinetics are recommended. Treatment effectiveness is low and short-term. Analyses of patients'

${ }^{*}$ Corresponding author. complaints suggest that the low therapeutic effect could be due to the fact that the treatment consists mainly of drugs [2]. This also applies to the irritable bowel syndrome, functional diarrhoea, constipation. One additional treatment option would be dietetic food. Dietetic foods are defined as foods that due to the specific content or the special manufacturing process are clearly distinguishable from other types of food and are intended for the particular use by persons with impaired digestive or metabolic process, or for persons who, while in a special physiological condition, should receive controlled nutrients [3].

In Latvia as well as in the European Union states, and, presumably, elsewhere regulatory base have been developed, but clinical trials are very rare despite the broad supply of dietetic foods. In the wide range of publications, it is not easy to find such studies [4]. Most dietary recommendations are based on the indirect evidence of 
the possible beneficial effects of the dietetic food ingredients towards user's body and its functions. Recommendations for dietetic food use based upon research data are evidently needed, and it was necessary to explore the dietetic food application in the gastroenterology clinics. For one of these studies we were offered the dietetic food product "Vitamarine" for evaluation.

\section{Literature Overview}

\subsection{Dyspepsia and Dyspeptic Like Complaints}

The term "dyspepsia" is used to describe a set of rather diversely formulated gastrointestinal complaints $[5,6]$. The causes could be organic (known, provable) and functional (not known or difficult to prove). The most typical differential diagnostic sign (characteristic) is the duration of the "functional" disease as the complaints go on for several years without serious deterioration in health [7]. More attention has been paid regarding "functio nal dyspepsia", meaning dyspeptic complaints from the upper gastrointestinal tract in patients for whom no correlation between diagnosed organic changes (especially no associated esophagogastroduodenoscopy (EGDS) data) could be found. In Western countries $25 \%$ of functional dyspepsia patients with gastrointestinal complaints could be found [8]. The study difficulty is that often functional dyspepsia and irritable bowel syndrome complaints appear to overlap for the same patients. For example, half of the functional dyspepsia patients have, also, irritable bowel syndrome symptoms [9]. Despite the vast number of studies and publications, up to date there is no acceptable classification of these pathologies [10] or the classifications are controversial.

Treatment of dyspeptic complaints is still a problem, being usually incomplete, and only in $60 \%$ of the cases with even short-term efficacy [11]. Best short-term results after the first visit to the primary care physician was $82 \%$ improvement which the authors attributed to good patient cooperation and the use of proton pump inhibitors [12]. This is largely due to the completely unclear aetiological factors and pathogenesis, where complex interacttions between diverse psychosocial factors, somatisation (other disorders) and sensorimotor gastric functions exist (the latter often being the least significant factor) [13]. Multiple existing studies about the gastric motor functions are of little use in the everyday clinical practice and patient's dietary habits and such factors as food intolerance are often fully ignored [14]. There are only a few double-blind randomized studies about the treatment of functional dyspepsia with herbal products [15]. Not only functional dyspepsia usually associated with the upper abdominal regions (more precisely epigastrium), but also the so-called "lower" dyspepsia exists. Here belong obstipation affecting almost $27 \%$ of the population and still presenting treatment difficulties [16].

Taking into the account the above mentioned vague definition, classification and diagnostic criteria of dyspepsia as well as a repeated evaluations and re-assessments of large study research findings that point to serious methodological problems in this regard [17], we chose the most common gastrointestinal symptoms in order to study the effectiveness of vitamarine. Fatigue, weakness and rapid tiredness are common complaints [18] that usually reflect some somatic pathology. In cases of prolonged chronic weakness (chronic fatigue syndrome) for patients with depression, it can be the cause of suicide [19].

Epigastric pain [20], the most frequent symptom that characterise dyspepsia, is included in the new Rome III classification of functional dyspepsia [21,22] as well as early sensation of epigastric fullness that, too, belong to the diagnostic criteria for functional dyspepsia.

Burning sensation behind the sternum (heartburn) is a classic gastroesophageal reflux disease (GERD) symptom that affects $60 \%-90 \%$ of the patients [23]. The symptom of burning feeling in the epigastrium is similar to the heartburn and is often associated with carditis (inflammation of the gastric cardia) or gastritis. Two possible reasons for carditis are noted: H. pylori induced inflammation and gastroesophageal reflux disease [24]. Meteorism is perceived as increase of intestinal gases with the feeling of bloating, flatulence, sometimes the feeling of distension or stomach expansion [25] that cause undefined abdominal pain. Constipation, defined as failure to achieve 3 adequate bowel movements per week, is a fairly common occurrence for the irritable bowel syndrome with constipation, and based on the Rome III classification criteria easily diagnosed, but the treatment is problematic [26]. The prospective hopeful new drugs mentioned in the same publication (2007) have not been confirmed. Diarrhoea, the stool frequency more than 3 bowel movements per day or stool weigh more than $200 \mathrm{~g}$ per day, is a common symptom but with very diverse causes. Unintended weight loss is one of the so-called "red flag" (dangerous) symptoms. Nowadays weight loss could be specially induced with different techniques or drugs and the said means could be overused, too.

\subsection{About the Seaweed Products}

Vitamarine is seaweed product (Laminaria spp.- - sea tangle, edible brown seaweed) that contains many microand macro elements such as iodine, calcium, iron, selenium, etc., biologically active substances, polysaccharides (fucoidin, laminarin, alginic acid), vitamins-A, B1, B2, B12, C, D, E, as well as a number of amino acids. The seaweeds have been used as food since ancient times, 
either without prior preparation ("sea cabbages", "kelp") or as specially manufactured products. The Laminaria products are offered on the market both single and in combined preparations [27]. The dietetic preparation (homogenised laminaria with spirulina and micro elements) evaluated in our study is registered in the Latvian republic under the trademark name "Vitamarine" and is being produced by "The Sum of Technologies, Ltd." (scientific production venture), legal address - $1^{\text {st }}$ Avenue named after Botkin, house 2/6, Moscow, 125284, RF, in compliance with the technological conditions mandatory for food production and dietetic food preparation, i.e. for the production of homogenised laminaria with spirulina and micro elements intended for human consumption as prophylactic and therapeutic nutrition in order to obtain additional source of soluble fibres, alginates, micro elements and iodine in the organic form, for the optimization of gastrointestinal tract functions and normalization of carbohydrate and lipid metabolism. Extended product name: "Vitamarine-homogenised laminaria with spirulina, selenium, chrome, copper, zinc and manganese". This seaweed product offered for our study was obtained from Laminaria spp. using low-temperature hydrolysis-technology that enabled the gel from seaweed to keep all the elements in natural proportions and concentration. This gel contains $94.7 \%$ moisture, up to $2 \%$ ashes and no less (calculated on a dry weight) than $35 \%$ of alginic acid, in the form of sodium alginate-calcium alginate, $1 \%-1.5 \%$ fibre, $1 \%$ protein, mineral macro \& microelements, vitamins. Nitrogen containing substances are represented by 18 amino acids, among which 8 amino acids are essential (irreplaceable) ones. Alginic acid released during the Laminaria processing defines the main features of the seaweed gel.

Alginates that comprise $35 \%$ share of the gel components possess the unique enterosorbent properties to bind heavy metals, toxic and radioactive substances forming complex assemblies. As alginates are not absorbed in the gastrointestinal tract, but eliminated with faeces, all the substances bound with alginates are freely excreted from the body. Therefore the seaweed gel can be used for rapid detoxification of the body from lead, mercury, cobalt, methanol, as well as uranium derived radioactive elements [28]. This applies not only to the toxic substances that enter the human body with food and water, but also to the toxins in the intestinal tract that come from other organs, tissues, blood. Alginic acid and its salts (alginates) ion-exchange properties are the most important ones from the medical point of view [29]. Unlike other sorbents having the stability constant with potassium, alginic acid binds harmful to humans "heavy" metals without interfering with the potassium-calcium exchange mechanisms and pathways. Experiments show that alginates can absorb not only solid (stable) metals, but also isotopes [30]. Functional properties of the alginates do not change during the food processing with heat therefore alginates can be used not only as enterosorbent substances, but also included in the food products. Alginic acid combined with antacids is used for the symptomatic treatment of gastroesophageal reflux disease in order to form a protective barrier. For example this effect has been used in a relatively well-known medication Gaviscone [31].

Laminaria component fucoidan has antioxidant properties [33] and can reduce apoptosis [32] or more precisely laminaria treated cells have higher antioxidant enzyme activity [34]. Bacterial flora associated with laminaria exhibit interesting antimicrobial properties [35]. Gel from seaweeds is being used as a food additive in the production of mayonnaise and sausages or baking bread. Seaweed products in medicine are used for prophylaxis and treatment. Reviewing "Medline" database for the term "laminaria" 654 publications were found on July 15, 2009, as well as 9613 "Medline" database publications regarding the term "dyspepsia". Similar Medscape data search on May, 2013, showed 780 publications for "laminaria" and 10.449 about "dyspepsia" and various treatment uncertainties, still, associated with this matter, but the publication increase was only quantitative.

The longest studies, including randomized controlled trials [36,37], and most extensive practical use of the seaweed preparations so far have been in obstetrics: different sized sterile tampons for cervical opening and priming prior to delivery, for stenosis treatment, before intrauterine manipulations, for drainage and abrasions, childbirth easing. One of these preparations is Norskan Laminaria, the US Food and Drug Administration approved product (K951330). The mechanism of these tampons/swabs is based upon the product's ability to absorb fluids and increase in size almost $4 \mathrm{x}$ times during 6 24 hours [38,39]. Experimental studies point to the effectiveness of the seaweed products for hepatopathies [40] and diabetes mellitus [41]. Some publications can be found about the use of laminaria in other diseases: in stomatology [42] for paradonthosis treatment, in nephrology as additional enterosorbent diet therapy [43], in dermatology [44], in pulmonology as a biologically active food supplement added to the pulmonary tuberculosis treatment with positive effect [45]. One publication was about the dilatation of oesophageal and laryngeal strictures [46]. No studies about the clinical safety were found. Only the safety of Laminaria extracted fucoidan has been evaluated, stating that dosage of $300 \mathrm{mg}$ per body weight kg was without side effects, but larger doses statistically creditably prolonged the blood coagulation (clotting time) [47]. Most significant adverse reactions have been noted while using laminaria swabs for cervical dilatation: urticaria, angioedema, respiratory disorders 
associated with type I reactions, IgE-related hypersensitivities [48], anaphylaxis have been described (although the most severe anaphylactic reactions as well as hypersensitivities are very rare, because the research shows that alginic acid actually has anti anaphylactic properties [49]). For healthy Japanese adults who were using laminaria product "Kombu" $15 \mathrm{~g}$ per day for 55 - 97 days reversible suppression of thyroid function was observed [50]. Laminaria products are not recommended for patients with renal insufficiency (may increase serum potassium levels).

\subsection{Application of the Seaweed Gel for the Treatment of Gastrointestinal Diseases}

During the recent years treatment of gastrointestinal tract diseases has gained special relevance in many countries, including the Baltic region. Dietary foods should take more defined place in the treatment and prevention of digestive disorders. Almost 1500 differently named natural products are recommended for people with digestive problems, 600 of these are said to improve liver function.

There have been a number of clinical trials of the seaweed gel use for the gastrointestinal tract diseases. The experimental group of 123 patients with a wide range of gastrointestinal pathologies included 63 patients treated with the seaweed gel while the control group comprised of 60 patients treated with the following: diet No. 3, biological agents, micro enemas, physical procedures, antispasmodics and laxatives if necessary. Treatment with the seaweed gel induced the following positive changes: normalization of the bowel movements was noted in $98.1 \%$ of the patients, the feeling of partial intestinal emptying disappeared in $92.4 \%$ of the patients. Endoscopic and morphological survey data confirmed positive colon mucosal dynamics marked with the decrease of mucosal inflammation of the colon (89.4\%), healing of the erosions $(100 \%)$ or inflammatory cell infiltration reduction $(74.8 \%)$.

The seaweed gelnormalized chemical changes in the stool: faecal $\mathrm{pH}$ returned to normal for $98.3 \%$ patients, organic acid and ammonia levels improved for $98.5 \%$, no tissue proteins were found and mucine remained in stool only in $4.7 \%$ of the patients. Due to the antibacterial properties of sodium alginate the seaweed gel is effective in treatment of the intestinal dysbacteriosis caused by conditionally pathogenic microflora. It is important to note that particularly susceptible were staphylococci, haemolytic streptococci, proteus and their associations. Ulcer healing time was shorter for the experimental group patients and the scarring or stricture deformity was less pronounced. For ulcerative colitis patients such symptoms as pain, intestinal bloating and dyspeptic complaints decreased significantly. Assessing the total im- provement rate for the sample patient group, authors noted positive clinical changes for patients with gastrointestinal tract disorders: the seaweed gel was effective in gastrointestinal diseases, haemorrhoids, chronic constipation in adults and children.

There is evidence that alginate solutions are beneficial for the main intestinal microbiota, while inhibiting the activity of optional micro-organisms such as Staphylococci, Salmonella, Candida and others. Antibacterial properties of sodium alginate, one of the seaweed gel key components, have been investigated. Sodium alginate exhibits antimicrobial properties even in insignificant concentrations $(0.125 \%)$, creating a protective layer of mucus. The properties of algal cellulose (algulesis) differ from plant cellulose and can be used in the treatment of chronic constipation. Laminaria water extract as a therapeutic agent with antioxidant, anti-angiogenic and anti-tumour effect was patented in 2004 in the Baltic States and Russian Federation [51].

The obtained study results provide basis for recommendations for seaweed gel food as a therapeuticpreventive dietary product to be included in the complex treatment of patients with gastrointestinal diseases, haemorrhoids, anal fissure, as there is positive effect on faecal chemical changes, the GI tract microbiota improvement and biocenosis normalization. In the treatment of gastrointestinal tract disorders the seaweed gel has shown analgesic, antispasmodic and regenerating effects, restoring homeostasis, preventing intestinal dysbiosis, regulating motor function $[52,53]$.

The prophylactic vitamarine course with $1-2$ months duration has manufacture recommended dosage 50 - 100 g 1 - 2 times per day and the therapeutic course with duration of 3 - 6 months (after 1 month break repeated course is suggested) has dosage $100-150 \mathrm{~g} 1-2$ per day. As part of complex treatment dose may be increased to $200 \mathrm{~g}$ per day. The above mentioned interested us and we explored the impact on functional gastrointestinal complaints.

\subsection{Assessment of the Dietary Food Effect}

Usually, while evaluating dietary food as well as food additives and dietary supplements, no requirements are set for clinical efficacy and safety.

However while analysing dietary preparation from laminaria (vitamarine), we took into account the following: 1) long-term evidence-based clinical use in obstetrics and gynaecology, 2) several therapeutic effects noted for these products in gastroenterology, and decided to use the evaluation methodology commonly applied to drug testing, also, for the vitamarine study.

\section{Study Hypothesis, Aims and Objectives}

Study hypothesis: dietary food "Vitamarine" reduces 
digestive tract complaints and improves the general feeling of well-being while using economic (50 g per day) dose. Project aim: to study vitamarine's clinical effectiveness for the patients with most common gastrointestinal symptoms. Research objectives: 1) to find eligible patients-study participants; 2) to include the patients in the study; 3) to make observations for at least 8 - 10 days, i.e. with one control; 4) vitamarine exposure assessment: after 8 - 10 days of use, after longer use, evaluation of the factors that may affect the results with discriminant analysis; 5) vitamarine safety evaluation.

\section{Method and Patients}

1) Research type: an open, uncontrolled (pilot study)

Investigated product and its use: dietary food Laminaria homogenized with spirulina and trace micro elements - "Vitamarine", manufactured by "The Sum of Technologies, Ltd.". The product differs from similar ones as it is produced in an easily assimilated gel form with high bioavailability. Proposed use of the study product: 2 tablespoons (25 - $30 \mathrm{~g}$ of the gel) half an hour before mealtime 2 times a day (total amount of $50-60 \mathrm{~g}$ of product per day), preferably in the natural gel form, but if the taste of seaweeds is unacceptable, then mixed with water or low acid content juice.

Patients: Out-patients of both sexes

2) Inclusion criteria

- Fatigue, easy tiredness, weakness (months/years long)

- Dyspeptic symptoms (epigastric pain, feeling of pressure in the epigastrium, rapid feeling of fullness) and/or

- Constipation and/or diarrhoea (months/years long complaints)

- Meteorism: flatulence, bloating, abdominal distension (months/years long complaints)

- Burning sensation in the epigastrium

- Burning sensation behind the breast bone (heartburn)

- Abdominal pain (mild, undefined)

- Age from 18 to 75 years

- Agreement to participate in the clinical observation 3) Exclusion criteria

- Younger than 18 and older than 75 years

- Any of the following risk factors present (jaundice, anaemia- $\mathrm{Hb}<100 \mathrm{~g} / \mathrm{L}$ ), prolonged severe pain or very severe abdominal pain, nausea/vomiting, dysphagia, odynophagia)

- Hypersensitivity to iodine and iodine preparations

- Contraindications to the use of iodine preparations

- Any type of the seaweed product intolerance

- Cirrhosis of the liver (documented and/or complications-ascites)

- Any localization of malignant tumours

- Pregnancy and lactation

- Doubts about the patient's cooperation
- Unresolved chronic alcoholism, drug addiction or medication addiction

- Currently are using seaweed products

\subsection{Study Design}

- Patients with gastrointestinal complaints aged between 18 and 75 years are introduced to the planned clinical study outline and, if the agreement to take part in the study is obtained, informed consent form is signed.

- In case of consent, exclusion criteria are checked.

- Necessary laboratory analyses are carried out, recent analyses made just prior to the study enrolment may be used.

- Once again exclusion criteria are verified.

- If the patient is eligible for inclusion in the study, the patient is interviewed completing the study questionnaire.

- One drug packaging for 10 day use is issued to the patient with the admonition to arrive for the control visit after 8 - 10 days.

- The patient is warned that in all cases of uncertainty and, also, if he/she cannot attend the next visit, the assigned study doctor and/or the project manager should be contacted.

- During the next visit the patient's general condition is assessed, patient interviewed and the questionnaire filled out.

- Together with the patient the following decisions are made: 1) either for the study conclusion or continuation, 2) agreement to maintain the study dosage. If the observation is continued, new product package is issued and the next visit time set.

- If the patient neither arrives for the agreed upon visit, nor contacts the study personnel setting up a new date, 2 days after the designated visit time information is gathered via telephone.

- If the patient withdraws from the study, the general well-being assessment report is obtained.

Overall work procedure summary is depicted in Table 1.

Blood and urine samples will be obtained with the doctor's prescription in the usual order. Participation in this project is completely voluntary; examination of the sample analyses will be confidential. Names of the participants will not be revealed in the reports about the study results. Only the treating physician and authorized institutions will have access to the documents containing information regarding the patient's identity.

\subsection{Statistical Data Processing}

All data are presented as "signs", for example-patient's gender, a woman or a man, and as "sign gradation", 
Table 1. Summary of the study work procedure.

\begin{tabular}{|c|c|c|c|}
\hline Study control & $\begin{array}{l}\text { Entry control inclusion: } \\
\text { First visit Day } 0\end{array}$ & $\begin{array}{l}\text { Control visits } 2,3,4,5,6,7,8,9,10 \\
11 \text {, i.e. every } 8-10 \text { days, }( \pm 2) \text { days }\end{array}$ & $\begin{array}{l}\text {, Last study control visit } \\
\text { (Paragraph } 74 \text { of the questionnaire) }\end{array}$ \\
\hline $\begin{array}{l}\text { Informed patient consent } \\
\text { (see Appendix) }\end{array}$ & $\square$ & - & - \\
\hline $\begin{array}{l}\text { Questionnaires. Inclusion and exclusion criteria } \\
\text { (see above) }\end{array}$ & $\square$ & - & - \\
\hline $\begin{array}{l}\text { Baseline objective data: BMI calculation } \\
\text { (an exclusion criterion), height and weight }\end{array}$ & $\square$ & $\square$ & $\square$ \\
\hline $\begin{array}{l}\text { Medical history data and the subjective } \\
\text { evaluation of the symptoms }\end{array}$ & $\square$ & $\square$ & $\square$ \\
\hline $\begin{array}{l}\text { Clinical blood tests and biochemical analyses } \\
\text { (optional) }\end{array}$ & $\square$ & - & - \\
\hline Study preparation issue & $\square$ & $\square$ & - \\
\hline Used study product/packaging control & - & $\square$ & $\square$ \\
\hline Patient survey regarding the side effects during use & & $\square$ & $\square$ \\
\hline Decision for the continuation of the study & - & $\square$ & - \\
\hline
\end{tabular}

using the "Patient Observation Card" (see). The coded data are entered in the MS Excel format; afterwards the coded data are processed by multivariate analysis program "Kulbak" assessing the data reliability/credibility (p) and data informativity (s). Findings with a p-value of $\leq 0.05$ are considered to be statistically significant. The obtained study results are considered to be informative at $\hat{\mathrm{I}}>1.0$. If even statistically reliable informativity is less than " $\hat{\mathrm{I}}$ " in the multivariate analysis system, as there are a relatively small number of patients.

Research venues: VSIA Pauls Stradins Clinical University Hospital, Gastroenterology, Hepatology and Nutrition Centre and Latvian Maritime Medicine Centre.

\subsection{Legal Aspects of the Study}

1) Study permit from the Clinical Research Ethics Committee of Pauls Stradins Clinical University Hospital was obtained on January 16, 2009; Address: Pilsonu street 13, Riga, LV-1002, telephone: +371 67611353.

2) The investigated product is a dietary food allowed for use in the Latvian republic.

3) Because vitamarine is not a drug, no permission from the State Agency of Medicines was required, and the following regulations do not apply to this study, i.e. Regulations regarding the Conduct of Clinical Trials and Non-interventional Trials, the Procedures for the Labelling of Investigational Medicinal Products and the Procedures for Inspection of Conformity with the requirements of Good Clinical Practice, Cabinet of Ministers Nr.172, Riga, February 28, 2006 (Minutes Nr.12 29th §); Amendments: Regulations Nr.17 of the CM 15.01.2008 [54].

Project sponsor: Advanced Technology Centre "Vita Li-Riga", Ltd., Reg.No. LV 40003730357 Address: Matisa street 21, Riga, LV-1001, Phone: + 37167007171.
Research support: "Gastroenterology Support Society", Registry. No. LV40008038191 Address: Upeslejas street 2 - 28, Stopinu county, Riga region, LV-2118, www.gastroenterologs.lv.

\section{Results}

Study observations included 46 patients. Data about 45 patients (one patient did not appear to the control visit) were analysed: 26 (57.8\%) women and 19 (42.2\%) men aged between 23 to 73 years. $63.4 \%$ of the patients were younger than 55 years. Half of the patients $(50.0 \%)$ used only a single package during the course. The overall evaluation was carried out taking into account 78 features with the minimum intensity gradation being 2 , the maximum intensity gradation-5. The number of patient's answers regarding various signs was different.

After 8 - 10 days of vitamarine use $33(76.8 \%)$ patients noted complete loss of the symptoms or symptom improvement, but for 10 patients (23.2\%) no improvement or increased symptoms were noted. Evaluating the situation in more detail, we obtained the results shown in Table 2 and depicted in Figure 1.

Vitamarine use was more often ineffective for a statistically significant number of patients with normal leukocyte count in the blood, no weight loss, no history of diabetes mellitus, and the said patients, also, had a tendency $(p=0.07)$ to withdraw from further use of vitamarine after 8 - 10 days of the course.

Using discriminant analysis, factors that could affect "Vitamarine" impact during the 8 - 10 day course were compared, i.e., we searched the group of patients with improvement (33) versus failure group (10). There were no improvement for the non-diabetic patients $(\mathrm{p}=0.02)$, for patients with normal white blood cell count $(\mathrm{p}=0.05)$, no weight loss $(\mathrm{p}=0.03)$ and no epigastric pain $(\mathrm{p}=$ 
Table 2. Vitamarine exposure assessment, according to the subjective self-perception data of 43 patients (feature 72 . and 74 .), after 8 - 10 days, at the end of the whole course (\%).

\begin{tabular}{ccccc}
\hline $\begin{array}{c}\text { Evalution } \\
\Rightarrow\end{array}$ & $\begin{array}{c}\text { Complete } \\
\text { loss of the symptoms } \\
(\%)\end{array}$ & $\begin{array}{c}\text { Partial } \\
\text { improvement of the symptoms } \\
(\%)\end{array}$ & $\begin{array}{c}\text { Without } \\
\text { improvement } \\
(\%)\end{array}$ & $\begin{array}{c}\text { Increased } \\
\text { symptoms } \\
(\%)\end{array}$ \\
\cline { 1 - 2 } $\begin{array}{c}\text { Course duration, dosage: } \\
8-10 \text { days }\end{array}$ & 25.6 & 51.2 & 16.3 & 6.9 \\
$500 \mathrm{~g}$ & $\mathrm{~N}^{*}=11$ & $\mathrm{~N}=22$ & $\mathrm{~N}=7$ & $\mathrm{~N}=3$ \\
$>8-10$ days & 25.6 & 48.8 & $\mathrm{~N}=7$ & 9.3 \\
$1000 \mathrm{~g}$ and $>$ & $\mathrm{N}=11$ & $\mathrm{~N}=21$ & $\mathrm{~N}=4$ \\
\hline
\end{tabular}

*Number of patients.

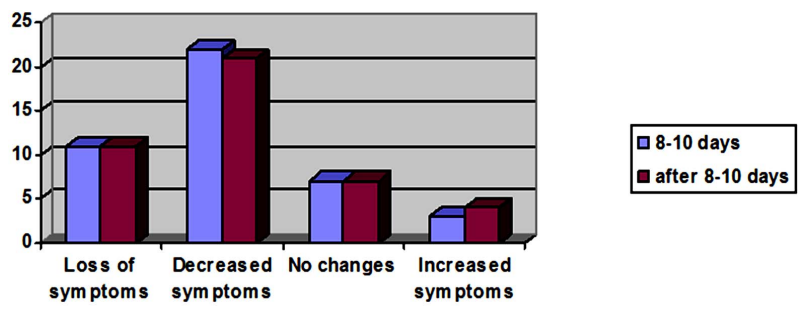

Diagram 1. Vitamarine efficacy assessment after the 8 - 10 day course and the entire course according to subjective self-assessment of 43 patients (feature 72 . and 74.) in chart form (\%).

$0.03)$, i.e. for the "healthier" patients.

In the same way, discriminant analysis was used for the comparison of factors that might influence the effect of longer course of vitamarine and the results were very similar to the findings regarding the $8-10$ day course: no improvement for non-diabetic patients $(\mathrm{p}=0.02)$, with a normal white blood cell blood count $(p=0.02)$, no weight loss $(\mathrm{p}=0.02)$, and no epigastric pain $(\mathrm{p}=0.03)$.

\section{Analysis of the Individual Symptoms and Features}

1) Patients' gender did not affect vitamarine efficacy and safety. Creditable statistical tendency and high informativity $(\mathrm{p}=0.08, \hat{\mathrm{I}}=7.43)$ indicate longer use of vitamarine by women.

2) Patients' age gradations were: younger than 20 years (none), 20 - 29, 30 - 39, 40 - 49, 50 - 59, 60 - 69, 70 - 79, 80 - 89 and older. Inter-group analysis, as expected, showed statistically significant increase in the number of illnesses after 50 years.

3) Comparing patients younger than 55 years with older ones: the latter credibly participated in the treatment for at least $2-4$ weeks $(p=0.05, \hat{\mathrm{I}}=10.12)$ and used no less than 2 - 3 vitamarine packages.

4) Patients' body mass index (BMI) gradation did not affect vitamarine efficacy and safety, and high BMI (> 30.0) also did not affect the results; no patients with low BMI and malnutrition took part in the study.

5) Regular use of medicines did not affect vitamarine efficacy and safety; it is interesting to note that long-term drug use is associated with years long constipation ( $\mathrm{p}=$ $0.01, \hat{\mathrm{I}}=6.02$ ).

6) Use of non-steroid anti-inflammatory drugs (NSAID) during the last two months did not affect vitamarine efficacy and safety. Patients taking NSAIDs during the last 2 months, used vitamarine irregularly $(p=0.06)$. Informative and reliable data about the normalisation of bowel movements and disappearance of constipation were noted $(\mathrm{p}=0.04, \hat{\mathrm{I}}=1.51)$.

7) Antibiotics use during the last 6 months, did not affect vitamarine effects and safety.

8) Antibiotics used for H. pylori eradication did not affect vitamarine efficacy and safety; informative and reliable data indicate that the use of antibiotics were, also, due to abdominal pathology $(\mathrm{p}=0.01, \hat{\mathrm{I}}=6.08)$ and is associated with unexplained weight loss $(\mathrm{p}=0.01)$.

9) Antibiotics used in connection with dysbacteriosis (only 4 patients) had no effect on vitamarine efficacy and safety, but indicated reliable informative trend towards increased abdominal pain after the course $(\mathrm{p}=0.06, \hat{\mathrm{I}}=$ 12.79).

10) Antibiotics used due to abdominal pathology (prior to the study) for 18 patients did not affect vitamarine efficacy and safety, but, as shown already, correspond to statistically significant data regarding $\mathrm{H}$. pylori eradication $(p=0.01, \hat{I}=11.84)$ and, also due, to the treatment of dysbacteriosis.

11) Antibiotics used in connection with non-abdominal pathology for 17 patients did not affect vitamarine efficacy and safety.

12) Repeated antibiotics courses (17 patients) mainly were for patients with dysbacteriosis (associated with diarrhoea and/or irregular bowel movements $\mathrm{p}=0.05, \hat{\mathrm{I}}=$ 7.86).

13) The history of post-antibiotics diarrhoea episodes for 8 patients did not affect vitamarine efficacy and safety.

14) The history of allergic reactions to medications for our group was very interesting: from 43 answers we got information that 17 patients $(39.5 \%)$ had evidence of some allergic manifestation, but it did not affect statistically vitamarine efficacy and safety and were not associated with other signs. 
15) Prior medical history was noted for 21 (50.0\%) patients, which included a variety of diagnosed illnesses: diabetes mellitus (2), chronic pancreatitis (5, statistically significant $(\mathrm{p}=0.02, \hat{\mathrm{I}}=13.91)$ for more that $60-69$ years of age) with secretory insufficiency (4) various liver diseases (6); in addition a history of ulcerative colitis (5) and Crohn's disease (1), repeated gastric operations (2) and rheumatoid arthritis (2) in no way did affect vitamarine effectiveness and safety, neither as a whole nor in the disease groups (from feature 16 till 21).

22) All the 45 patients included in the study had complaints (100\%).

23) Complaints about weakness, fatigue and early tiredness for $26(60.5 \%)$ patients statistically significantly $(\mathrm{p}=0.04)$ and informatively $(\hat{\mathrm{I}}=3.48)$ disappeared after 8 - 10 days of vitamarine use; prior duration of the complaints for months or years (feature 24) did not affect vitamarine efficacy and safety.

25) Complaints about abdominal pain for 15 (36.6\%) patients did not affect vitamarine effectiveness and safety; duration of the complaints for months or years (feature 26) did not interfere with vitamarine efficacy and safety.

27) $11(25 \%)$ patients complained about diarrhoea and/or unformed bowel movements that had lasted for months and years (feature 28), but it did not affect vitamarine efficacy and safety.

29) Patients' complaints about the feeling of rapid fullness (15 patients, 34.1\%), which had generally lasted for years (feature 30 for 14 patients), did not affect vitamarine efficacy and safety, but this tendency $(\mathrm{p}=$ $0.06, \hat{\mathrm{I}}=8,88$ ) remained valid also after the course.

31) Patients' complaints about epigastric pain (11, $22.7 \%$ ) did not affect vitamarine efficacy and safety, but analysis of the duration of the individual complaints (feature 32) revealed that the months long (4 patients) complaints statistically significantly decreased $(p=0.02$, $\hat{\mathrm{I}}=9.54)$ and the yearlong complaints ( 7 patients) disappeared after the vitamarine course $(p=0.06, \hat{\mathrm{I}}=$ 4.77).

33) Patients' $(11,25.0 \%)$ complaints of epigastric burning did not affect vitamarine efficacy and safety, but was closely related to the months long constipation ( $\mathrm{p}=$ $0.03 \hat{\mathrm{I}}=8.45$ ), and these patients had no EGDS data about ulcers $(\mathrm{p}=0.01)$. Duration of the heartburn (feature 34) did not affect vitamarine efficacy and safety.

35) Patients' (15.34.1\%) complaints about the burning sensation behind the breastbone (GERD symptoms) did not affect efficacy and safety, but showed an informative $(\hat{I}=1.14)$ tendency $(p=0.1)$ to decrease after $8-10$ day vitamarine course. Prior complaint duration (feature 36) did not influence vitamarine effectiveness and safety, but was creditably associated with the length of the other complaints: a) abdominal pain $(\mathrm{p}=0.05, \hat{\mathrm{I}}=6.99)$, and $\mathrm{b})$ diarrhoea and/or unformed bowel movements $(p=0.05, \hat{I}$
=6.99) and other likely symptoms, but this tendency was valid only for year-long complaints.

37) Patients' complaints $(6,13.6 \%)$ about constipation did not affect vitamarine efficacy and safety. For patients with year-long constipation (feature 38) more frequent drug use $(\mathrm{p}=0.01, \hat{\mathrm{I}}=6.02)$ and a history of diagnostic EGDS $(p=0.05, \hat{\mathrm{I}}=6.99)$ are characteristic, and statistically reliable and informative $(p=0.01, I=7.79)$ data show that months long constipation disappears after vitamarine use.

39) Patients' $(6,14.0 \%)$ complaints about undefined and/or variable/changing bowel movements did not affect vitamarine efficacy and safety; analysis of the duration of the individual complaints presented similar results (feature 40).

41) Patients with unexplained weight reduction (6, $13.8 \%$ ) did not affect vitamarine efficacy and safety, however highly informative associations with the burning sensation behind the sternum $(p=0.02, \hat{I}=10.79)$ and the burning sensation in the epigastrium $(\mathrm{p}=0.01, \hat{\mathrm{I}}$ $=11.76$ ) are noted.

42) For patients with meteorism, noted in 38 patients out of the 43 responders $(88.4 \%)$, no negative impact on vitamarine efficacy and safety or significant associations with other features were found. Year-long meteorism complaints (feature 43) were statistically relevant $(\mathrm{p}=$ $0.01, \hat{I}=6.02$ ) for the patients with additional complaints of years long rapid feeling of fullness and less than a yearlong burning sensation behind the breast bone $(\mathrm{p}=$ $0.01 ; \hat{\mathrm{I}}=11: 46)$.

44) Only $3(8.3 \%)$ patients had low haemoglobin, and it did not affect vitamarine efficacy and safety, but is statistically reliably and informatively associated with a burning sensation behind the breast bone $(\mathrm{p}=0.02, \hat{\mathrm{I}}=$ $10.79)$ and burning in the epigastrium $(\mathrm{p}=0.02, \hat{\mathrm{I}}=$ 9.54).

45) Normochromic anaemia was present in 1 patient.

46) 3 patients had increased erythrocyte sedimentation rate $(\mathrm{ESR})>20 \mathrm{~mm} \mathrm{~h}$, and it was significantly higher for patients with long years of meteorism $(\mathrm{p}=0.04)$.

47) $\mathrm{C}$ reactive protein $(\mathrm{CRO})>5 \mathrm{mg} / \mathrm{dL}$ occurred in 4 patients and did not affect vitamarine efficacy and safety.

48) Increased number of white blood cells (leucocytosis) was only diagnosed in 1 patient.

49) Out of the 34 answers $17(50 \%)$ patients denied Helicobacter pylori infection, 3 patients $(8.8 \%)$ were informed about its presence, the other ones either had no reliable knowledge or lacked diagnostic tests, but it did not affect vitamarine effectiveness and safety, although the data were statistically more frequent for chronic pancreatitis $(p=0.05)$ and liver patients $(p=0.05)$.

50) At various times EGDS had been performed for a total of $31(75.6 \%)$ patients, and it did not affect vitamarine efficacy and safety. Analysing the EGDS inves- 
tigation timing (feature 51), significantly more frequently $(\mathrm{p}=0.02, \hat{\mathrm{I}}=10.41)$ patients with a burning sensation behind the breastbone had been investigated during the recent weeks.

52) The following EGDS findings were noted: normal EGDS $(\mathrm{n}=5 \%, 16.7 \%)$, inflammation (gastritis, duodenitis-13, 43.3\%), erosions $(10 \%, 33.3 \%)$ and ulcers $(2 \%, 6.7 \%)$, and subgroup analysis shows that it did not affect vitamarine efficacy and safety. Patients with gastro duodenal ulcers significantly more frequently declined further vitamarine use $(p=0.05, \hat{I}=1.14)$.

53) Oesophageal pathology was found in $5(17.9 \%)$ patients, all the patients had reflux esophagitis, and it had no effect on the efficacy and safety of vitamarine use. 4 reflux esophagitis patients had mild disease and 1 patient a severe form (feature 54) with no tendency $(\mathrm{p}=0.1, \hat{\mathrm{I}}=$ 2.39) towards the general health improvement. This patient also had vitamarine intolerance.

55) Only 1 patient from all the patients with EGDS had ulcers and/or active scars in the gastro duodenal zone and showed a tendency to partial overall improvement $(\mathrm{p}$ $=0.09, \hat{\mathrm{I}}=2.71$ ).

56) Erosions in the gastro duodenal area were found for $11(37.9 \%)$ patients with EGDS and it did not affect vitamarine efficacy and safety.

Features from 57 up to 69 are analysed while assessing features 71 and 73 (general assessment).

70) $10(23.8 \%)$ patients discontinued further vitamarine use, but it was not linked to product intolerance.

72) The clinical observation duration (use of vitamarine) was: 1 - 2 weeks-25 (61.0\%) patients, 4 weeks-7 (17.1\%) 6 weeks-2 (4.9\%) 8 weeks-2 (4.9\%) and more-5 (12.2\%). Patients with constipation that lasts for months $(\mathrm{p}=0.03, \hat{\mathrm{I}}=8.45)$ creditably used vitamarine more than 2 weeks.

73) See above

74) $70.7 \%$ of patients regularly used vitamarine and it did not affect vitamarine efficacy and safety. Patients who used the preparation irregularly were also tended to reduce vitamarine dosage $(p=0.06, \hat{I}=6.64)$ and had a slight tendency for side-effects $(\mathrm{p}=0.09, \hat{\mathrm{I}}=0.68)$.

75) Vitamarine dose reduction (patient reduces the dosage himself) did not affect its efficacy and safety.

76) Diverse side effects were marked in 10 patients out of 42 responses $(23.8 \%)$ and it did not affect vitamarine effectiveness. Side effects were mild and disappeared after vitamarine discontinuation. Statistically significant, but not informative features associated with adverse reactions, were: elevated white blood cell count $(p=0.02)$ and weight loss $(p=0.02)$. These patients had a tendency to rapid sensation of fullness $(p=0.06)$ with high informativity ( $\hat{\mathrm{I}}=9.95)$.

Vitamarine provoked symptom increase only for 1 patient $(2.7 \%)$ and the preparations use had to be discontinued. This group include also 5 (10.9\%) patients who named as side effects: vitamarine taste peculiarities, increased appetite and weight gain. Remaining sensation of fullness in the upper abdominal regions after vitamarine course is statistically significantly associated with the adverse events defined by patients as such $(p=0.03$, I $=7.91$ ) and, conversely, patients did not remark upon any side effects if the sensation of rapid epigastric fullness was absent $(p=0.04, \hat{I}=5.46)$. This situation is mainly due to chronic pancreatitis patients $(\mathrm{p}=0.04)$ and complications of the disease-pancreatic secretory insufficiency $(p<0.05)$, but uninformative because of the small patients number.

77) $30(75 \%)$ patients would agree to take part in another clinical trial of vitamarine.

78) The number of used vitamarine packages did not affect efficacy and safety.

\section{Discussion}

Clinical trial of the dietetic food "Vitamarine" included 46 patients. Data of 45 patients were analysed (one patient did not appear for control visit). The total number of patients comprised of $26(57.8 \%)$ women and 19 (42.2\%) men aged between 23 to 73 years, $63.4 \%$ of patients being younger than 55 years, which is comparable to the overall Latvian patient population.

After 8 to10 days of vitamarine use or "short course" $33(76.8 \%)$ patients noted symptom improvement or complete disappearance and only $10(23.2 \%)$ patients had no improvement or symptom increase. At the end of the observation the results were also similar. It should be noted that this result was achieved with a minimal preventive daily dosage of $50 \mathrm{~g}$ instead of a therapeutic dose that can be up to $200 \mathrm{~g}$ per day. In addition, only half of the patients continued to take vitamarine longer than 8 - 10 days, although the recommended prophylactic vitamarine course duration is at least a month.

Our results are lower than those presented in literature, but, it should be noted that in these previous studies, patients also received combined treatment. In our situation only 2 patients with ulcerative colitis received additional basic treatment with mesalazine. The improvement was not statistically significant for the patients without diabetes mellitus, without weight loss and abdominal pain and with normal white blood cell count, i.e. for the healthier" patients. Longer vitamarine course results present similar picture: no improvement for patients without diabetes, without weight loss and abdominal pain and with normal white blood cell count.

The specific effect of Laminaria spp. "to help the sick and do no harm to the healthy ones" was remarked upon first in the study in 1969 [55], though later controversial data abounded [56-58]. Patients without the positive 
effect tend to withdraw from further vitamarine use after 8 - 10 day course $(p=0.07)$. Since our study was without control group, it raises the question about the placebo effect. In functional dyspepsia patients, the placebo effect is between $35 \%$ - $40 \%$ (for herbal products even $16 \%$ $71 \%$ ) and it does not depend on the gender, age, previous symptoms, but is reduced in patients with low body weight [59]. From this point of view also vitamarine effectiveness can be termed as high.

\section{Analysis of the Factors That Could Affect Vitamarine Gel Function}

Patient's gender and age did not affect vitamarine effectiveness and safety. Statistically reliable data indicate longer use of vitamarine by women. Despite the fact that elderly patients had an increased number of illnesses, it left no impact on the treatment outcome.

Patient's BMI gradation did not affect vitamarine efficacy and safety, and high BMI (>30.0) also did not affect the results, but we must point out that no patients with low BMI and malnutrition took part in the study.

Regular use of other drugs (mainly NSAIDs and antibiotics) did not affect vitamarine efficacy and safety; it is interesting to note with high statistical confidence $(\mathrm{p}=$ 0.01 ) and informativity ( $\hat{I}=6.02$ ) that long-term drug use is associated with yearlong constipation. Conversely, in patients treated with NSAIDs, statistically creditable disappearance of constipation was observed in our study. In a very large study of 10,007 patients the questionnaires revealed dyspeptic complaints in $24.9 \%$ of patients, but multivariate analysis showed the use of NSAIDs to be the major cause of dyspepsia, then smoking $(>20$ cigarettes per day) and unemployment and only lastly $\mathrm{H}$. pylo ri infection [60]. A history of diarrhoea after the antibiotics course did not affect vitamarine efficacy and safety.

History of allergic reactions to the medications was a frequent finding in our patient group $(39.5 \%)$, but it did not affect statistically vitamarine efficacy and safety and were not associated with other signs. The above mentioned can be regarded as a very good finding. Perhaps the alginic acid does have anti-allergic properties, as shown by experimental data [61].

$21(50.0 \%)$ patient had extended medical history, that included diabetes, chronic pancreatitis, liver disease, ulcerative colitis and Crohn's disease, repeated gastric surgery and rheumatoid arthritis, but it did not affect vitamarine effectiveness and safety, neither as a whole nor in the disease groups. There is evidence in literature that dyspepsia occurs more frequently in patients with somatisation [62]. Vitamarine impact upon individual symptoms are summed up in the Table 3.

$26(60.5 \%)$ patients complained about fatigue, weakness and early tiredness, that statistically creditably disappeared after 8 - 10 days of vitamarine use notwithstanding the months or years long duration of the complaints that did not affect vitamarine efficacy and safety. Taking into account the abundant, biologically diverse, nutritional content described in the literature, this finding was planned for and verified our working hypothesis.

Canadian researchers have found that fatigue is a very common symptom for the irritable bowel syndrome patients with drug intolerance [63] (in our study, "allergic to the medicines").

Complaints about abdominal pain for 15 (36.6\%) patients and the duration of these complaints did not

Table 3. Vitamarine impact on the individual symptoms.

\begin{tabular}{|c|c|c|}
\hline Features/symptoms/expressions & Impact/efficacy & Credibility and informativity \\
\hline Fatigue, weakness and early tiredness & Disappears after 8 - 10 days & $\mathrm{p}=0.04 ; \hat{\mathrm{I}}=3.48$ \\
\hline Functional diarrhoea & No change in status & NS \\
\hline Rapid feeling of fullness (in epigastrium) & Tendency to remain & $\mathrm{p}=0.06 ; \hat{\mathrm{I}}=8.88$ \\
\hline Epigastric pain & $\begin{array}{l}\text { Months long pains decrease significantly; } \\
\text { tendency for yearlong pains to decrease }\end{array}$ & $\begin{array}{l}\mathrm{p}=0.02 ; \hat{\mathrm{I}}=9.54 \\
\mathrm{p}=0.06 ; \hat{\mathrm{I}}=4.77\end{array}$ \\
\hline Burning (heartburn) sensation in the epigastrium & No change in status & $\mathrm{NS}$ \\
\hline Heartburn (burning sensation behind the breastbone) & Tendency to decrease after $8-10$ days & $\mathrm{p}=0.1 ; \hat{\mathrm{I}}=1.18$ \\
\hline Functional constipation & Disappears for months, long-term effect & $\mathrm{p}=0.01 ; \hat{\mathrm{I}}=7.79$ \\
\hline Undefined or changing bowel movements & No change in status & NS \\
\hline Unexplained weight loss & No change in status & NS \\
\hline Meteorism/flatulence & No change in status & NS \\
\hline
\end{tabular}


affect vitamarine effectiveness and safety. Since this symptom belongs to the so-called "red" flag symptoms and is associated with an increased risk of serious pathology, certainly prescription of vitamarine without the doctor's consultation in this situation is risky, even though there arose no security concerns for our patients.

$11(25 \%)$ patients complained about diarrhoea and/or unformed bowel movements that had lasted for months and years, but it did not affect vitamarine efficacy and safety. Our study indicates that this complaint belongs mainly to the irritable bowel syndrome patients and evaluation of vitamarine for these patients requires a separate study. Patients' complaints about the sensation of rapid fullness (15 patients, 34.1\%), which for 14 patients had lasted for years, did not affect vitamarine efficacy and safety, but this tendency $(p=0.06, \hat{I}=8,88)$ remained valid also after the course. Rapid sensation of fullness after a small food intake is a classic sign of functional dyspepsia and most creditably can be observed after "greasy" food intake [64]. There is no doubt that the best treatment results of functional dyspepsia in this situation would be achieved with prokinetic agents such as metoclopramide or domperidone.

Patients' complaints about epigastric pain did not affect vitamarine efficacy and safety, but the analysis of the duration of individual complaints indicates the following trend: if the complaints were long-term (years) they disappear, but, if those complaints were just months long, they decrease statistically significantly $(\mathrm{p}=0.02, \hat{\mathrm{I}}$ $=9.54$ ). It should be noted that this is a classic functional dyspepsia complaint. For these patients, Cochran randomized placebo-controlled trial data meta-analyses confirm the effectiveness of proton pump inhibitor therapy [55], although the reasons for these pains may be very different [58]. Patients' complaints about the burning feeling in the epigastrium did not affect vitamarine efficacy and safety, but were closely related to months long constipation $(\mathrm{p}=0.03, \hat{\mathrm{I}}=8.45)$, and these patients had no EGDS finding of ulcers $(p=0.01)$. This symptom is typical for functional dyspepsia and common for the gastroesophageal reflux disease, its treatment of choice being proton pump inhibitors.

Patients' complaints of heartburn (burning sensation behind the breastbone), which is a classic GERD symptom, did not affect vitamarine efficacy and safety and shows creditable tendency to decrease after 8 - 10 days of the course. Perhaps it can be attributed to the vitamarine sodium alginate component's ability to form a protective mucous layer as well as its adsorbent properties, which have been studied and are used in the clinical practice, for example Gaviscon [59].

Patients' complaints about month's long constipation disappear after using vitamarine. Statistically significant data confirm this impact of vitamarine without compro- mising its safety. Best results were achieved by patients who used vitamarine for 2 - 4 weeks. That is also consistent with literature data. Statistically significant findings indicate that patients with yearlong constipation had more frequently used drugs and performed diagnostic EGDS. It is possible that the small number of patients did not allow us to get more certain results. Impairment of bowel movements in functional dyspepsia patients is common as these complaints are detected for 4 out of 5 patients with dominating constipation (34\%) [62].

Patients' complaints about undefined and/or variable bowel movements which could be classified as possible signs of the irritable bowel syndrome did not affect vitamarine efficacy and safety and neither did the analysis of the complaints duration.

Unexplained body weight loss, which also belongs to the "red" flag symptoms [61], did not affect vitamarine efficacy and safety, and statistically reliably correlated with the burning sensation in epigastrium or behind the breastbone. It should be noted that a credible link between weight loss and dyspepsia [62] (in our case it can be attributed to the burning sensation in epigastrium) has been found. On the web one can find a large number of advertising publications regarding the "slimming properties" (weight loss) of Laminaria gel. Also, some of our patients remarked that "the stomach became smaller", but it was not associated with objective weight loss. On the other hand, 2 patients with high BMI remarked upon appetite improvement as an "undesirable" phenomenon.

Meteorism, which was found in 38 patients out of the 43 responses $(88.4 \%)$, did not affect vitamarine efficacy and safety, and were not significantly associated with other features. It is possible that extension of the course could give additional effect in this case. Several patients noted "stomach reduction" effect, which hypothetically could be due to the irritable bowel syndrome, however the aetiology of meteorism include a lot of different diseases, and this observed patient group is quite small making subgroup analyses impossible.

Low haemoglobin was found only in $3(8.3 \%)$ patients and its level did not influence vitamarine safety and effectiveness, and is creditably associated with the burning sensation behind the breast bone $(p=0.02, \hat{I}=10.79)$ and burning sensation in the epigastrium $(p=0.02, \hat{I}=9.54)$.

Increased ESR was observed in 3 patients and did not affect vitamarine efficacy and safety, but was creditably more frequent in patients with years long flatulence $(\mathrm{p}=$ 0.04). 4 patients had elevated CRP, but it did not affect vitamarine efficacy and safety.

Half of the patients thought that they had no Helicobacter pylori infection, 3 patients $(8.8 \%)$ were informed about its presence, the other ones had either no reliable knowledge or lacked diagnostic tests, but it did not affect vitamarine effectiveness and safety, although data were 
significantly higher for chronic pancreatitis $(\mathrm{p}=0.05)$ and liver patients $(\mathrm{p}=0.05)$. It should be noted that the type of dyspeptic complaints do not differ for the H. pylori-infected and non-infected patients [63], but more severe dyspeptic symptoms are characteristic for the most virulent strains of these bacteria [64].

At various times EGDS has been performed for a total of $31(75.6 \%)$ patients, and it did not affect vitamarine efficacy and safety. Normal endoscopic findings were only noted for $16.7 \%$ patients. In comparison with the study in Poland this percentage was higher-23\% [65], but the reason for this is the prevalence of elderly patients in our study. Analysing EGDS investigation time frame, statistically significant data show that during the last weeks this investigation was performed mainly for the patients with a burning sensation behind the breastbone.

EGDS findings were analysed regarding their impact towards the effectiveness and safety of the vitamarine. Significant data that patients with gastroduodenal ulcers more frequently discontinue further vitamarine use $(\mathrm{p}=$ $0.05, \hat{I}=1.14$ ) were found. The pathological findings in the oesophagus for all the patients were similar i.e. reflux esophagitis, but with no impact on vitamarine efficacy and safety. Interestingly enough, complete vitamarine intolerance was observed in the patient with a very severe reflux esophagitis. In contrast the patient with an active scar in the gastro duodenal area exhibited a tendency towards general improvement. $37.9 \%$ patients with EGDS investigation had erosions in the gastroduodenal area and it did not affect vitamarine efficacy and safety. Literature data more often than not show correlations with ulcerous scars and reflux esophagitis with the background of complete general dyspeptic symptom divergence from the endoscopic picture [66].

$10(23,8 \%)$ patients discontinued further vitamarine use, but it did not affect vitamarine efficacy and safety, and was not connected with intolerance in this case.

Duration of the clinical study (vitamarine use): $1-2$ weeks-25 (61.0\%) patients; 4 weeks-7 (17.1\%); 6 weeks-2 (4.9\%); 8 weeks-2 (4.9\%) and longer-5 $(12.2 \%)$ and it did not affect vitamarine efficacy and safety. Statistically significantly longer that 2 weeks vitamarine was used by patients with months long obstipation $(\mathrm{p}=0.03 ; \hat{\mathrm{I}}=8.45)$.

$70.7 \%$ of the study patients regularly used vitamarine and it did not affect gel efficacy and safety. Patients, who were using vitamarine irregularly, tended to reduce the recommended dosage themselves and exhibited a slightly more frequent trend to report side effects. Vitamarine dosage decrease (patient tapers the dose himself), did not affect vitamarine efficacy and safety, it being extremely important for the preparation that is not a medication but a dietetic foodstuff. Patient co-operation level in our study should be termed as a high one, because the ano- nymous questionnaire of the Latvian inflammatory bowel disease patients revealed only $60,8 \%$ level of compliance [67].

Diverse undesirable side effects or complaints were noted for 10 patients out of 42 responders (23.8\%), but it did not affect vitamarine function. Adverse reactions were mild and either disappeared while proceeding with the vitamarine course or after vitamarine course discontinuation. Statistically believable, but not informative features/signs associated with side effects were increased WBC count in blood $(\mathrm{p}=0.02)$ and unexplained weigh loss $(p=0.02)$. These patients also exhibit a tendency towards the sensation of rapid fullness. Vitamarine aggravated symptoms only for 1 patient $(2.7 \%)$ and its use had to be discontinued. This group also includes $5(10.9 \%)$ patients who named as side effects peculiar taste of vitamarine, appetite increase and weight gain. Subjectively the patients described their sensations very diversely and these feelings are summed up in the Table 4.

Remaining sensation of rapid fullness in the upper abdomen after the vitamarine course is statistically significantly associated with the side events noted by the patients $(\mathrm{p}=0.03,=7.91)$ and, conversely, patients do not point out side effects if there is no sensation of rapid epigastric fullness $(p=0.04, \hat{I}=5.46)$. More detailed analysis shows that this situation is due to the patients with chronic pancreatitis $(p=0.04)$ and its complications pancreatic secretory malfunction/insufficiency $(p<0.05)$, but data are not informative because of the small number of patients.

Overall the high level of vitamarine efficacy can be also due to the fact that functional dyspepsia, gastroesophageal reflux disease and irritable bowel syndrome complaints mainly overlap and, using only one, even the "best" or "gold" standard treatment option, could be very

Table 4. Patients subjective sensations noted as side effects in the study.

\begin{tabular}{|c|c|c|}
\hline Nr. & Subjective feelings/sensations & $\begin{array}{l}\text { Patient } \\
\text { number }\end{array}$ \\
\hline 1. & "...sensation of something being stuck in the throat" & 1 \\
\hline 2. & Constipation & 1 \\
\hline 3. & "An unpleasant taste in the mouth" & 1 \\
\hline 4. & $\begin{array}{l}\text { Oily stool, aholia } \\
\text { (for patient with chronic pancreatitis } \\
\& \text { secretory insufficiency) }\end{array}$ & 1 \\
\hline 5. & "...not possible to drink" & 2 \\
\hline 6. & $\begin{array}{l}\text { "*at first pain in the back intensified, } \\
\text { then completely disappeared" }\end{array}$ & 1 \\
\hline 7. & "*.. feeling of the thyroid gland" & 1 \\
\hline 8. & Appetite improvement and weight gain & 3 \\
\hline 9. & Distension feeling (severe meteorism) & 2 \\
\hline 10. & Loose stools, which resolved within 2 days & 1 \\
\hline
\end{tabular}


effective for one symptom or symptom group while the risk of other symptom persistence remains. $75 \%$ of the patients would agree to participate in another clinical vitamarine trial, which correlates with the achieved efficiency level. This is a very high percentage of consent, which can be indirectly attributed to the general interest about such natural products and the beneficial effect of this particular dietetic preparation.

Some study limitations, also, should be remembered: this relatively small number of patients did not represent all age groups in equal manner; the non-homogenous group as well as the disparity of the symptoms; lack of ability to obtain more precise data from the participants regarding prior specific antibiotics usage in part of the cases as the patients were not able to provide these data for us. However in this pilot project we wanted more to explore the perception of well-being (subjective optimal health as perceived by the patients) according to the symptoms, but not the standardised unspecific health questionnaires. Focus was on the patients sensations and feelings associated with their gastrointestinal functions.

The number of used vitamarine packages did not affect efficacy and safety. It is possibly due to the fact that half of the patients' vitamarine course was only $8-10$ days, while for other patients the entire course length varies. From the user's point of view as very important should be termed the fact that in most cases even with the very first dietary food packaging positive effect is achieved.

Finally, it should be noted that our study evaluating vitamarine was only a pilot study that likewise indicates the potential dietary benefits as well as the possible risks. In order to further clarify the effectiveness of this interesting product, further observations and studies of clearly defined target groups, taken from the overall dyspeptic patient population, should be performed, and it is necessary to proceed with research $[68,69]$.

\section{Conclusions}

1) Vitamarine is a dietetic food whose dosage of 50 - 60 $\mathrm{g}$ per day in 2 cases out of 3 improves the user's general condition.

2) Vitamarine is effective for early tiredness, fatigue and weakness, month's long dyspeptic abdominal pains and constipation disappear or decrease.

3) Vitamarine dose of 50 - $60 \mathrm{~g}$ per day even for the first 8 - 10 days shows effectiveness that practically varies little with the courses continuation.

4) Vitamarine use is safe also for patients with a history of allergies to medications, the elderly, and for patients with concomitant diseases.

\section{REFERENCES}

[1] K. A. N. Nyrop, O. S. Palsson, R. L. Levy, M. V. Korff, A. D. Feld, M. J. Turner and W. E. Whitehead, "Costs of
Health Care for Irritable Bowel Syndrome, Chronic Constipation, Functional Diarrhoea and Functional Abdominal Pain," Alimentary Pharmacology \& Therapeutics, Vol. 26, No. 2, 2007, pp. 237-248. doi:10.1111/j.1365-2036.2007.03370.x

[2] A. P. S. Hungin, C. Hill and A. Ragunath, "Systematic Review: Frequency and Reasons for Consultation for Gastro-Oesophageal Reflux Disease and Dyspepsia," Alimentary Pharmacology \& Therapeutics, Vol. 30, No. 4, 2009, pp. 331-342. doi:10.1111/j.1365-2036.2009.04047.x

[3] 2009. http://www.websitelibrary.lv/pateretaja-celvedis.lv

[4] 2009.

http://www.google.lv/search?q=food+diet+dietary\&hl=lv \&start $=40 \&$ sa $=\mathrm{N}$

[5] N. B. Vakil, "Upper GI Disorders: New Directions in the Management of Dyspepsia and GERD. DDW2007," 2009. http://www.medscape.com/viewarticle/556302

[6] E. M. M. Quigley and J. Keohane, "Dyspepsia," Current Opinion in Gastroenterology, 2009.

http://www.medscape.com/viewarticle/584173

[7] M. Pajala, M. Heikkinen and J. Hintikka, "A Prospective 1-Year Follow-Up Study in Patients with Functional or Organic Dyspepsia: Changes in Gastrointestinal Symptoms, Mental Distress and Fear of Serious Illness," Alimentary Pharmacology \& Therapeutics, Vol. 24, No. 8, 2006, pp. 1241-1246.

doi:10.1111/j.1365-2036.2006.03108.x

[8] M. Zvolinska-Wcislo and D. Galicka-Latala, "Epidemiology, Classification and Management of Functional Dyspepsia," Przeglad Lekarski, Vol. 65, No. 12, 2008, pp. 867-873.

[9] M. Corsetti, P. Caenepeel, B. Fischler, J. Janssens and J. Tack, "Impact of Coexisting Irritable Bowel Syndrome on Symptoms and Pathophysiological Mechanisms in Functional Dyspepsia," The American Journal of Gastroenterology, Vol. 99, No. 6, 2004, pp. 1152-1159. doi:10.1111/j.1572-0241.2004.30040.x

[10] L. A. Van Kerkhoven, R. J. Laheij, V. Meineche-Schmidt, S. J. Veidhuyzen-Van Zatlen, N. J. de Wit and J. B. Jansen, "Functional Dyspepsia: Not All Roads Seem to Lead to Rome," Journal of Clinical Gastroenterology, Vol. 43, No. 2, 2009, pp. 118-122. doi:10.1097/MCG.0b013e31815591f7

[11] K. Monkemuller and P. Malfertheiner "Drug Treatment of Functional Dyspepsia," World Journal of Gastroenterology, Vol. 12, No. 17, 2006, pp. 2594-2700.

[12] L. Agreus, N. J. Talley, A. Sheen, S. E. Johansson, M. P. Jones and K. Svardsudd, "Predictors and Non-Predictors of Symptom Relief in Dyspepsia Consultations in Primary Care," Digital Distribution, Vol. 26, No. 3, 2008, pp. 248-255. doi:10.1159/000121355

[13] L. Van Oudenhove, J. Vandenberghe, B. Geeraerts, R. Vos, P. Persoons, B. Fischler, K. Demyttenaere and J. Tack, "Determinantsof Symptoms in Functional Dyspepsia: Gastric Sensomotor Function, Psychosocial Factors or Somatisation?" Gut, Vol. 57, No. 12, 2008, pp. 1666 1673. doi:10.1136/gut.2008.158162

[14] C. Feinle-Bisset and M. Horowitz, "Dietary Factors in 
Functional Dyspepsia," Neurogastroenterology \& Motility, Vol. 18, No. 8, 2006, pp. 608-618. doi:10.1111/j.1365-2982.2006.00790.x

[15] A. Madisch, G. Holtmann, G. Mayr, B. Vinson and J. Hotz, "Treatment of Functional Dyspepsia with a Herbal Preparation. A Double-Blind, Randomized, Placebo-Controlled, Multicenter Trial," Digestion, Vol. 69, No. 1, 2004, pp. 45-52. doi:10.1159/000076546

[16] J. Tack and S. Müller-Lissner, "Treatment of Chronic Constipation: Current Pharmacologic Approaches and Future Directions," Clinical Gastroenterology and Hepatology, Vol. 7, No. 5, 2009, pp. 502-508. doi:10.1016/j.cgh.2008.12.006

[17] N. S. Abraham, P. Moayyedi, B. Daniels and S. J. O. Veldhuyzen Van Zanten, "The Methodological Quality of Trials Affects Estimates of Treatment Efficacy in Functional (Non-Ulcer) Dyspepsia," Alimentary Pharmacology \& Therapeutics, Vol. 19, No. 6, 2004, pp. 631-641. http://www.medscape.com/viewarticle/472650

[18] 2009.

http://search.medscape.com/medline-search?newSearch = $1 \&$ queryText $=$ fatigue

[19] E. Fuller-Thomson and J. Nimigon, "Factors Associated with Depression among Individuals with Chronic Fatigue Syndrome: Findings from a Nationally Representative Survey," Family Practice, Vol. 25, No. 6, 2008, pp. 414422. doi:10.1093/fampra/cmn064

[20] C. H. Temml, "Epigastric Pain," Wiener Medizinische Wochenschrift, Vol. 151, No. 9-10, 2001, pp. 219-223.

[21] D. Drossman, "The Launching of Rome III," 2009. (http://www.romecriteria.org/pdfs/launch.pdf

[22] 2009. http://www.romecriteria.org/

[23] G. Holtmann, "Reflux Disease: The Disorder of the Third Millennium," European Journal of Gastroenterology \& Hepatology, Vol. 13, No. Suppl 1, 2001, pp. S5-S11.

[24] D. A. Owen, "Gastritis and Carditis," Modern Pathology, Vol. 16, No. 4, 2003, pp. 325-341. doi:10.1097/01.MP.0000062995.72390.14

[25] A. Agrawal and P. J. Whorwell, "Review Article: Abdominal Bloating and Distension in Functional Gastrointestinal Disorders-Epidemiology and Exploration of Possible Mechanisms," Alimentary Pharmacology \& Therapeutics, Vol. 27, No. 1, 2008, pp. 2-10. doi:10.1111/j.1365-2036.2007.03549.x

[26] B. D. Cash, E. Chang, N. J. Talley and A. Wald, "Fresh Perspectives in Chronic Constipation and Other Functional Bowel Disorders," Reviews in Gastroenterological Disorders, Vol. 7, No. 3, 2007, pp. 116-133.

[27] 2009. http://www.ec21.com/ec-market/laminaria.html

[28] S. K. Papageorgiou, F. K. Katsaros, E. P. Kouvelos, J. W. Nolan, H. Le Deit and N. K. Kanellopoulos, "Haevy Metal Sorbtion by Calcium Alginate Beads from Laminaria digitata," Journal of Hazardous Materials, Vol. 137, No. 3, 2006, pp. 1765-1772. doi:10.1016/j.jhazmat.2006.05.017

[29] A. V. Podkorytova, N. M. Aminina, M. M. Levachëv and V. A. Miroshnichenko, "Functional Properties of Alginates and Their Use in Therapeutic-Prophylactic Nutri- tion," Voprosy Pitaniia, No. 3, 199, pp. 26-29.

[30] S. K. Papageorgiou, F. K. Katsaros, E. P. Kouvelos, J. W. Nolan, H. Le Deit and N. K. Kanellopoulos, "Heavy Metal Sorption by Calcium Alginate Beads from Laminaria digitata," Journal of Hazardous Materials, Vol. 137, No. 3, 2006, pp. 1765-1772.

doi:10.1016/j.jhazmat.2006.05.017

[31] K. G. Mandel, B. P. Daggy, D. A. Brodie and H. I. Jacoby, "Review Article: Alginate-Raft Formulations in the Treatment of Heartburn and Acid Reflux," Alimentary Pharmacology \& Therapeutics, Vol. 14, No. 6, 2000, pp. 669-690. doi:10.1046/j.1365-2036.2000.00759.x

[32] K. H. Kim, Y. W. Kim, H. B. Kim, B. J. Lee and D. S. Lee, "Anti-Apoptotic Activity of Laminarin Polysaccharides and Their Enzymatically Hydrolyzed Oligosaccharides from Laminaria japonica," Biotechnology Letters, Vol. 28, No. 6, 2006, pp. 239-246.

[33] J. Wang, Q. Zhang, Z. Zhang and Z. Li, "Antioxydant Activity of Sulfated Polysaccharide Fractions Extracted from Laminaria japonica," International Journal of Biological Macromolecules, Vol. 42, No. 2, 2008, pp. 127132. doi:10.1016/i.ijbiomac.2007.10.003

[34] P. J. Park, E. K. Kim, S. J. Lee, S. Y. Park, D. S. Kang, B. M. Jung, K. S. Kim, J. Y. Je and C. B. Ahn, "Protective Effects against $\mathrm{H}_{2} \mathrm{O}_{2}$-Induced Damage by Enzymatic Hydrolysates of an Edible Brown Seaweed, Sea Tangle (Laminaria japonica)," Journal of Medicinal Food, Vol. 12, No. 1, 2009, pp. 159-166. doi:10.1089/jmf.2007.0675

[35] J. Wiese, V. Thiel, K. Nagel, T. Staufenberger and J. F. Imhoff, "Diversity of Antibiotic-Active Bacteria Associated with Brown Alga Laminaria saccharina from the Baltic Sea," Marine Biotechnology (New York), Vol. 11, No. 2, 2009, pp. 287-300.

doi:10.1007/s10126-008-9143-4

[36] A. Jonasson, "Laminaria-A Modern Cervix Dilatation Method with More than a 100-Year History," Jordemodern, Vol. 97, No. 6, 1984, pp. 187-195.

[37] A. M. Darwish, A. M. Ahmad and A. M. Mohammad, "Cervical Priming Prior Operative Hysteroscopy: A Randomised Comparison of Laminaria versus Misoprostol," Human Reproduction, Vol. 19, No. 10, 2004, pp. 23912394. doi:10.1093/humrep/deh397

[38] M. A. Burnett, C. A. Corbett and R. J. Gertenstein, “A Randomised Trial of Laminaria Tents versus Vaginal Misoprostol for Cervical Ripening in First Trimester Surgical Abortion," Journal of Obstetrics and Gynaecology Canada, Vol. 27, No. 1, 2005, pp. 38-42.

[39] 2009. http://www.laminaria.net/

[40] N. Kawano, Y. Egashira and H. Sanada, "Effect of Dietary Fiber in Edible Seaweeds on the Development of D-Galactosamine-Induced Hepatopathy in Rats," Journal of Nutritional Science and Vitaminology, Vol. 53, No. 5, 2007, pp. 446-450. doi:10.3177/jnsv.53.446

[41] D. Q. Jin, J. S. Kim, C. S. Yong, J. A. Kim and K. Huh, "Preventive Effects of Laminaria japonica Aqueous Extract on the Oxidative Activity in Streptozotocin-Induced Diabetic Rat Liver," Biological and Pharmaceutical Bulletin, Vol. 27, No. 7, 2004, pp. 1037-1040. doi:10.1248/bpb.27.1037 
[42] 2009. http://www.mediasphera.ru/journals/stomo/detail/256/3858/

[43] E. V. Rudichenko, T. A. Gvozdenko and M. V. Antoniuk, "Impact of Dietotherapy with Enterosorbent of Marine Origin on the Indices of Mineral and Lipid Metabolism for Patients Suffering from Kidney Diseases," Voprosy Pitaniia, Vol. 74, No. 4, 2005, pp. 33-35.

[44] M. Bonneville, P. Saint-Mezard, J. Etiere, A. Hennino, I. Pernet, A. Denis and J. F. Nicolas, "Laminaria Ochroleuca Extract Reduces Skin Inflammation," Journal of the European Academy of Dermatology and Venereology, Vol. 21, No. 8, 2007, pp. 1124-1125. doi:10.1111/j.1468-3083.2006.02111.x

[45] M. E. Lazovskaja, "Effectiviness of Using the Biologically Active Additive to Food from Laminaria in Adolescents during Complex Treatment of the Pulmonary Tuberculosis," Voprosy Pitaniia, Vol. 74, No. 1, 2005, pp. 40-43.

[46] F. Rodriques-Adrados, "Rapid Dilatation of Esophageal and Laryngo-Tracheal Strictures by Laminaria Tents," Revue de Laryngologie-Otologie-Rhinologie, Vol. 96, No. 9-10, 1975, pp. 1529-1534.

[47] Q. Zhang and J. Song, "Toxicological Evaluation of Fucoidan Extracted from Laminaria japonica in Wistar Rats," Food and Chemical Toxicology, Vol. 43, No. 3, 2005, pp. 421-426. doi:10.1016/j.fct.2004.12.001

[48] M. Chanda, P. Mackenzie and J. H. Day, "Hypersensitivity Reactions Following Laminaria Placement," Contraception, Vol. 62, No. 2, 2000, pp. 105-106. doi:10.1016/S0010-7824(00)00145-1

[49] H. J. Jeong, S. A. Lee, P. D. Moon, H. J. Na, R. K. Park, J. Y. Um, H. M. Kim and S. H. Hong, "Alginic Acid Has Anti-Anaphylactic Effects and Inhibits Inflammatory Cytokine Expression via Suppression of Nuclear FactorkappaB Activation," Clinical \& Experimental Allergy, Vol. 36, No. 6, 2006, pp. 785-794. doi:10.1111/j.1365-2222.2006.02508.x

[50] K. Miyai, T. Tokushige and M. Kondo, "Supression of Thyroid Function during Ingestion of Seaweed Kombu (Laminaria japonica) in Normal Japanese Adults," Endocrine Journal, Vol. 55, No. 6, 2008, pp. 1103-1108. doi:10.1507/endocri.K08E-125

[51] 2009. http://www.wipo.int/pctdb/en/wo.jsp?wo=2005099738

[52] "Use of Homogenized Brown Seaweed Gel in Therapeutic and Prophylactic Dietetic Nutrition," Medical Technologies Brochure, Moscow, 2006.

[53] 2009. http://www.rxlist.com/laminaria/supplements.htm

[54] 2009.

http://www.vza.gov.lv/doc_upl/MK_172_groz_not_17_1 50708.pdf

[55] W. H. Wang, J. Q. Huang, G. F. Zheng, H. H. Xia, W. M. Wong, X. G. Liu, J. Karlberg and B. C.Wong, "Effects of Proton-Pump Inhibitors on Functional Dyspepsia: A Meta-Analysis of Randomised Placebo-Controlled Trials," Clinical Gastroenterology and Hepatology, Vol. 5, No. 2, 2007, pp. 178-185. doi:10.1016/j.cgh.2006.09.012

[56] 2009.

http://search.medscape.com/medline-search?newSearch=
$0 \&$ queryText=laminaria

[57] 2009.

http://search.medscape.com/medline-search?queryText=d yspepsia

[58] 2009.

http://search.medscape.com/medlinesearch?queryText=ep igastric+pain

[59] J. P. Uspenski, I. G. Pakhomova and V. N. Bubiakina, "Alginate-Containing Preparation Gaviscon for Patients with Gastroesophaginal Reflux Complicated with Chronic Pancreatitis: Pathogenetic Substantiation of Clinical Use Prospects," Ekksperimental'naia i Klinicheskaîa Gastroènterologîa, No. 1, 2008, pp. 96-101.

[60] J. Hammer and N. J. Talley, "Disturbed Bowel Habits in Patients with Non-Ulcer Dyspepsia," Alimentary Pharmacology \& Therapeutics, Vol. 24, No. 2, 2006, pp. 405410. doi:10.1111/j.1365-2036.2006.02992.x

[61] V. Meineche-Schmidt and T. Jørgensen, “"Alarm Symptoms' in Patients with Dyspepsia: A Three-Year Prospective Study from General Practice," Scandinavian Journal of Gastroenterology, Vol. 37, No. 9, 2002, pp. 999-1007. doi: $10.1080 / 003655202320378167$

[62] M. P. Jones, N. J. Talley, G. D. Eslick, D. Dubois and J. Tack, "Community Subgroups in Dyspepsia and Their Association with Weight Loss," The American Journal of Gastroenterology, Vol. 103, No. 8, 2008, pp. 2051-2060.

[63] K. M. Hoffmann, A. J. Eherer and G. J. Krejs, “Are Dyspeptic Symptoms Linked to Helicobacter pylori? A Prospective Cohort Study among Medical Students," Wiener Klinische Wochenschrift, Vol. 115, No. 5-6, 2003, pp. 175-178. doi:10.1007/BF03040305

[64] G. Treiber, M. Schwabe, S. Ammon, S. Walker, U. Klotz and P. Malfertheiner, "Dyspeptic Symptoms Associated with Helicobacter pylori Infection Are Influenced by Strain and Host Specific Factors," Alimentary Pharmacology \& Therapeutics, Vol. 19, No. 2, 2004, pp. 219-231. doi:10.1111/j.1365-2036.2004.01751.x

[65] G. Piotrowicz, J. Milewski, B. Stepień and G. Rydzewska, "Characteristic and Endoscopic Evaluation of Dyspeptic Patients," Polski Merkuriusz Lekarski, Vol. 22, No. 127, 2007, pp. 15-20.

[66] T. Tahara, T. Arisawa, T. Shibata, M. Nakamura, M. Okubo, D. Yoshioka, F. Wang, H. Nakano and I. Hirata, "Association of Endoscopic Appearances with Dyspeptic Symptoms," Journal of Gastroenterology, Vol. 43, No. 3, 2008, pp. 208-215. doi:10.1007/s00535-007-2149-2

[67] E. Krustins, J. Derova, A. Pukitis and J. Pokrotnieks, "Patient Compliance in a Cohort of Patients in Latvia with Inflammatory Bowel Diseases," St. Petersburg, 2009. www.gastroenterology.ru/Gastro-2009_abstracts_090420

[68] H. Neumann, K. Monkemuller, A. Kandulski and P. Malfertheiner, "Dyspepsia and IBS Symptoms in Patients with NERD, ERD and Barrett's Esophagus," Digestive Diseases, Vol. 26, No. 3, 2008, pp. 243-247. doi: $10.1159 / 000121354$

[69] T. O. Lipman, "The Role of Herbs and Probiotics in GI Wellness for Older Adults: Herbal Use for the GI Tract," 2009. http://www.medscape.com/viewarticle/555222_6 